\title{
Descripción del medio Marroquí en Madrid
}

\author{
Por Encarna Cabello
}

La inmigración marroquí empezó a darse en España como fenómeno social, en los años en que comenzó la emigración española a Europa, es decir, finales de los 50 principios de los 60 , coincidiendo con el último auge del capitalismo.

La mano de obra marroquí resultó siempre barata para los empresarios españoles: peor pagados que los oriundos del país (sobreexplotación), sin seguros sociales en su inmensa mayoría. El capital quedaba con las manos libres para desembarazarse de estos trabajadores cuando la ocasión lo requiriera.

Eso fue lo que ocurrió a gran escala cuando llegó la recesión económica de los años 70. De igual modo que los emigrantes españoles en Europa tenían cada vez más dificultades para continuar en sus puestos de trabajo, aquí también se encarecían los Permisos de Trabajo y de Residencia, mientras que las autoridades marroquíes ponían trabas para la obtención de pasaportes: la llave para la emigración.

Por tanto, la estancia aquí pasó a ser ilegal para muchos de ellos, y el recuento del número total que suman en España y en las capitales en donde más se asientan, se hace difícil.

Sin embargo, como las malas condiciones económicas en Marruecos seguían e incluso aumentaban por razones interiores -empezaron tras la independencia (1956), con la salida del capital extranjero de las metrópolis francesa y española-, y también bajo la influencia de la crisis económica internacional del capitalismo, los marroquíes seguían y siguen viendo en la salida a Europa la única opor- 
tunidad de escapar a la miseria, aunque luego, en muchísimas ocasiones, resulte que la miseria a encontrar en las capitales europeas sea más difícil de soportar, pues aquí están sin la familia: ese seguro de desempleo que se da en los países del Tercer Mundo, así como en las sociedades marginadas y marginales.

Pero el hombre no puede pensar en pasar el resto de su vida viviendo de la solidaridad familiar, mucho más cuando piensa en casarse y en fundar una familia él a su vez, o cuando ya está casado y tiene unas responsabilidades de manutención con la mujer e hijos: esto resulta evidente cuando la propia cultura y la religión le exige cumplir con esas obligaciones, cuando en ello reposa en gran parte su virilidad.

La estadística de la población marroquí en España es difícil de hacer, pues se conoce el número de los que están en posesión del permiso de residencia y de trabajo: son unos 3.000, muchos de ellos son comerciantes rifeños y judíos, establecidos en el país desde hace muchos años, y con cierta vinculación entre ellos.

También puede saberse que aquellos que sólo cuentan con su pasaporte son aproximadamente unos $\mathbf{3 2 . 0 0 0}$.

Pero del resto que pulula por la Península, tras haber entrado clandestinamente, sin que su país se haya avenido a extenderles un pasaporte, que son detenidos, llegando a pasar en las cárceles españolas hasta períodos de algunos meses -ilegalmente según la Constitución de 1978 - antes de ser devueltos a su país, y que vuelven a entrar con tesón de mil maneras subrepticias, no hay recuento posible.

En Madrid, según datos de la Embajada marroquí, habría en total unos 3.600, incluídos los indocumentados, pero la opinión general de los propios marroquíes y los datos observados en publicaciones hace pensar que son unos 2.000 más. Barcelona supera a Madrid, cuenta, según los mismo datos oficlales, con unos 5.400 .

\section{TIPOS DE EMIGRACION}

La emigración ha sido fundamentalmente masculina, de hombres solos, ya fueran solteros o casados. Los primeros, o bien encuentran pareja aquí, mayormente entre españolas, pues el número de mujeres marroquíes en Madrid es pequeño y descompensado en comparación con el de hombres, o bien se casan en su país, trayendo a la mujer aquí, o dejándola en Marruecos, con su familia. Los hombres casados, tam- 
bién emigran solos en muchas ocasiones.

En cuanto a las mujeres, las hay también solteras y casadas. Las primeras emigraron bien con la familia, o solas. Entre las casadas, algunas vinieron con el marido, y otras llegaron solas a trabajar: huyendo de un matrimonio nada satisfactorio, o bien ya en condición de divorciadas.

\section{DISTRIBUCION URBANA Y MEDIOS DE VIDA}

Hay dos focos importantes de asentamientos marroquíes en Madrid: uno corresponde al barrio del Pilar, siendo en su casi totalidad matrimonios emigrantes. El nivel de instrucción es bajísimo, siendo casi siempre aún más bajo el de la mujer, que tiene menos contactos con los españoles. Ellos trabajan en la construcción, mayormente, y algunos en fábricas. Las mujeres lo hacen como empleadas externas del servicio doméstico.

El otro foco tiene como epicentro la zona del Rastro de Latina e inmediaciones. Aquí la composición es más variada, entran emigrantes solos y familias. La mayoría de ellos viven del comercio callejero, puestos en los Rastros, o en las calles céntricas.

Otros van y vienen con mercancías a Marruecos: llevan ropa y productos de España, que venden allí a buen precio, traen ropas y utensilios marroquíes que aquí llevan a los almacenes, éstos los venderán a otros marroquíes, que o bien disponen de una tienda, o bien lo venderán en la calle.

Ultimamente, con el nuevo sistema de venta de billetes de metro, bastantes de ellos que se encontraban sin ningún medio de vida, se lanzaron a la reventa de billetes, y hay que decir que esto les mantiene solucionadas sus vidas de momento. Algunos hay que trabajan en restaurantes, bares, y otros hay que lo hacen en actividades menos ortodoxas.

Las condiciones de alojamiento tanto de emigrantes solos como en familia son poco cómodas, pues los segundos se ven abocados a compartir con los hijos viviendas reducidas a su mínima expresión.

Los emigrantes sin familia viven en pensiones en la zona centro de la capital ya detallada antes. Estas pensiones apenas reúnen las mínimas condiciones para dormir y cocinar. Cocinando se pueden ahorrar dinero, además que es más cómodo y agradable poder prepa- 
rarse platos, incluso de cocina magrebina.

El estado higiénico, de luz y ventilación, es lamentable. Luz artificial deficiente: bombillas de pocas bujías, sin lámparas que hagan posible el estudio, apenas una mesa plegable e incómoda.

La mayoría de ellos comparten la habitación para que les salga más económico, lo que hace que la intimidad personal sea escasa, pues por una parte puede hacer nacer la amistad y confianza, pero también la suspicacia y agresividad, mucho más cuando ambos están viviendo en condiciones de supervivencia.

Por supuesto, que una habitación así no fomenta en absoluto el desarrollo intelectual del individuo: no hay posibilidad de concentración para pensar, leer o escribir. $Y$ al hacerse tan poco agradable la estancia allí, estos hombres prefieren salir a saborear el ambiente de las calles céntricas: vida de cafés, en donde encuentran a otros compatriotas en su misma o parecida situación, donde es posible la charla -uno se pone al tanto de las noticias de los otros paisanos- la bebida, y la distracción en general.

Otro tipo de colocación que encuentran en España los matrimonios marroquíes es el servicio doméstico interno: ellas como criadas y ellos trabajando de chófer y jardinero.

Las condiciones de la emigración marroquí en España son muy diferentes de las de esta misma población en países europeos como Holanda, Bélgica o Suecia. Una diferencia primordial es que mientras en estos países hay organismos especiales que se encargan de la emigración, creando toda una red de atenciones sociales, tanto para los emigrantes como para sus hijos, en España es la Dirección General de Seguridad quien se ocupa de la inmigración.

En la Europa Norte, el más alto nivel de vida, el número mayor de puestos de trabajo, confiere mayor bienestar económico y social a los emigrantes, sintiéndose éstos en posesión de unos derechos, lo que favorece en ellos una mayor conciencia social, que pueden encauzar de la manera que vean más conveniente.

\section{MUJERES EN LA EMIGRACION}

Su trabajo en la emigración es el servicio doméstico, pues carecen de títulos académicos y profesionales para realizar otro trabajo, y aquella que los tiene, compite en el mercado de trabajo con las españo- 
las, por tanto también se ve abocada a ello.

La mayoría son casadas, viviendo con el marido, y trabajando como externas.

Las solteras y divorciadas trabajan como internas, pues así se evitan preocupaciones de alojamiento y comidas, haciendo más ahorros. Además de ser esta situación para sus familias (más garante) de su buena conducta.

\section{CONVIVENCIA ENTRE MARROQUIES Y CON LOS ESPAÑOLES}

Los marroquíes, como cualquier población emigrante en general, donde quiera que estén en calidad de tal (Holanda, Bélgica, España, etc.) organizan su vida de cara a pasar el máximo de su tiempo con ellos mismos, y si se reunen con algún español -o europeo en general一, éste pertenecerá a su mismo «status» social - que suele coincidir con el del «lumpen», por lo que quedará IMPERMEABLE a la moral del país de residencia, tomando sólo de él actitudes exteriores, como son: salir con chicas «libremente», sentirse fascinado por la sofisticación de pubs, discotecas y otros lugares de diversión, crearse hábitos consumistas, etc. Pero sus prejuicios seguirán en pie.

Incluso a nivel de gente joven el contacto que se da es superficial, con una población que quiere ir de superficial, como son determinados grupos bastantes visibles en nuestra sociedad: llámese rokers, punks, etc. El intercambio cultural y de ideas es mínimo: por tanto, ni los jóvenes españoles aprenden nada nuevo de nuestros vecinos, con los que un día formaron parte de una sola cultura, ni los marroquíes se aproximan a la perspectiva de ideas y de vida a que se llega en el mundo occidental, tras la acumulación de experiencias.

El racismo se observa poco a nivel de la calle, contrariamente a la realidad de otros países, pero todos sabemos del fantasma del «moro» que ronda en la conciencia colectiva de los españoles, que puede manifestarse en cualquier momento, y que de hecho se manifiesta. Ellos tienen ocasión de comprobarlo en la misma clase social con la que más contacto tienen.

Yo también, en el tiempo que ha durado mi trabajo entre ellos, he tenido oportunidad de sentir pudor ante determinadas reacciones observadas en españoles, simplemente por el hecho de tratarse de 
marroquíes, ya fueran hombres o mujeres. Sus actividades laborales en España, son más o menos conocidas de todos, lo que levanta más suspicacias.

\section{ENTRE MARROQUIES}

Hay una agresividad originada y acumulada en su país, que emigra con ellos. Y puesto que el nuevo medio está lleno de obstáculos, y, por tanto, sigue siendo amenazador su entorno, las manifestaciones de esa agresividad se hacen sentir a la vista de todos.

Pero tal violencia no es un arma que sirva para liberarles de una situación injusta y en muchos casos asfixiante, no, no es liberadora, sino DESTRUCTIVA de ellos mismos, colabora con la máquina del sistema que crea su infelicidad.

Los encuentros se dan entre los mismos compatriotas. Se buscan tanto para abrirse camino en la supervivencia diaria como para pasar las largas horas de inactividad productiva, toda esa extensión de tiempo libre del que disponen, y que cubren en los cafés, atraídos por la familiaridad que ellos mismos crean.

Un café frecuentado por marroquíes no es el típico montado por la gran urbe en donde cada cual ocupa su plaza en la barra o en la mesa, y no la deja hasta la salida, en donde los grupos son cerrados y se reprueba con la indiferencia la interacción con los otros parroquianos.

Los marroquíes interaccionan entre ellos y con los españoles que por allí estén, si se prestan a ello. Es por esto que el café se convierte en lugar de estancia ideal, porque se da la reunión, la conversación, y cuando ésta se acaba, la soledad de uno con su vaso, y también se procura uno ciertas evasiones exhalando el humo de la hierba, en compañía de otros.

Tal contacto continuado e intensivo se da en un transfondo de desconfianza general entre ellos mismos: pueden pasar prácticamente todo el día juntos, y, sin embargo, no considerarse amigos. Es más, son ellos quienes cuando te acercas y entablas conversación intimista, espontáneamente sin tú plantearte esa cuestión — pues te parece tener delante camaradas unidos por la más estrecha complicidad-, te confiesan en actitud de víctima que no tienen amigos, que a lo mejor están más cerca de alguno, pero sólo depositarán en él una relativa confianza.

Esto puede entenderse en un medio de SUPERVIVENCIA, donde 
el otro es visto como un competidor, por tanto, como un enemigo en potencia. La amistad-fidelidad es difícil aquí, pero es necesario al menos contar con una persona de la que te puedas fiar, así aparece el amigo, ese del que se confía hasta cierto punto.

Es la ley de sálvese quien pueda. La poca confianza se convierte en sospechas de hostilidad cuando la susceptibilidad es herida en el menor detalle. Al siguiente contratiempo, la hostilidad ya es abierta, y el empleo de la fuerza no se hace esperar, o bien los puños, o una navaja, vengan el orgullo herido, sin el menor temor de ir a parar a la cárcel.

Aquí podríamos considerar la estrecha relación que guarda el machismo con su vertiente de salvar su orgullo de hombre y el pasar a defenderlo con los medios que sea. Nos encontramos, pues, de bruces con ese diálogo entre hombres que es el machismo. Son ellos quienes han de entenderse, y en esa dirección emplean el lenguaje propio de ellos, el de la agresión física, excluyendo el razonamiento, ya que no se escucha, no se emplea tal capacidad y queda atrofiada.

Así es como resulta evidente la vulnerabilidad de estos marroquíes para caer en prisión. Hablábamos antes de venganza, la venganza se transforma en «vendetta», pues el grupo familiar toma partido por el pariente agredido, sin querer saber los motivos de la disputa. Y no importa que mientras un hermano está luchando entre la vida y la muerte en un hospital, el otro se arriesgue a entrar en prisión en su afán de venganza, lo que importa es ésta en sí, que se convierte en justificación de la existencia.

La situación del emigrante es de INSEGURIDAD, por ello prefiere transitar a ser posible sólo por la zona ya conocida, por si algo pasa estar seguro ante cualquier eventualidad — nos referimos a la inseguridad social y psicológica-. 